\title{
Covid-19: Can France's ethical support units help doctors make challenging decisions?
}

France has set up "ethical support units" to help doctors make difficult choices about which patients with covid-19 to treat in intensive care. Sophie Arie reports

\section{Sophie Arie freelance journalist}

London

With more than 2600 deaths and 40000 cases of covid-19 recorded in France, hospitals in the Ile de France region surrounding Paris have been preparing for a tipping point in the week beginning Monday 30 March, when their 2000 intensive care unit (ICU) beds are expected to be full.

"We will have to make terrible choices about who will or will not be admitted to ICUs," Bertrand Guidet, head of the ICU at Saint Antoine Hospital in Paris, told The BMJ. "We have never had to make such difficult decisions."

Doctors will have to make far more decisions than usual on whether to treat patients or withdraw treatment from those who are too ill to benefit. But in addition, because of shortages of beds or ventilators, doctors will increasingly have to choose one patient over another when both could benefit from treatment.

Each of France's 13 regions will now have an "ethical support unit"-made up of experts in emergency medicine, geriatrics, palliative care, medical ethics, philosophy, ethics, and law, as well as representatives of patient groups and civil society-to support hospital staff, GPs, and the public as these decisions are made.

The units will also provide psychological support to medical professionals and will support the public and the state as they grapple with all sorts of ethical issues arising from the covid-19 epidemic. Two psychological support units, contactable by telephone, are also being set up in each region to support all medical workers as they work in crisis conditions that are widely being compared to wartime.

\section{Triage guidance}

University hospitals already have systems in place to support doctors who constantly make decisions. The regional ethical support units will provide additional reassurance to those hospitals in complex cases. These units may well be the only source of a second opinion for smaller hospitals, GPs, patients, and their families.
ICU doctors seeking reassurance about a decision or, for example, GPs who disagree with a refusal by paramedics to transport a patient to hospital because of a lack of beds, will be able to call their regional support unit, which will provide rapid advice to all involved.

Detailed recommendations for medical professionals on how to triage patients with covid-19 in an ethically acceptable way were issued to French doctors last week. ${ }^{1}$ Under the guidance, which Guidet helped to write, patients must be assessed on a combination of factors to decide which patients have the greatest chance of survival and the most life years to gain from surviving. These factors include:

- The patient's wishes

- The patient's baseline condition: age, frailty score (using the French clinical frailty score or GIR frailty score, the Katz index, and the World Health Organization's performance index score if already known), nutritional status, and cognitive status

- The severity of the virus: respiratory failure and organ failure, measured using a SOFA (sequential organ failure assessment) score

- The potential life years to be gained, and

- The availability of beds and ventilators.

Depending on how each patient measures against others on the above criteria combined, the patient should either be admitted to ICU, receive palliative care only, or be offered care that does not require intubation. If a patient is dying the guidance specifies that at least one relative should be allowed to be present, using suitable protective equipment.

One of the peculiarities of covid-19, says Guidet, is that many patients need 3-4 weeks of intensive care. The guidance advises that ICU patients should be reassessed every two days and that treatment should be withdrawn if they no longer meet the criteria for treatment. 


\section{Appeals for clarity}

In Paris, to try to maximise ICU capacity, hospitals are considering whether two patients could share a ventilator (a procedure already approved for use in New York ${ }^{2}$ ) and whether tracheotomies could be carried out to help wean patients off ventilators when they are ready, says Guidet.

In Normandy, where hospitals have not yet reached full capacity, the ethical support unit currently provides more of a public communications role. It has responded to appeals from the public for clarity on issues such as how many relatives may attend births or visit newborns in maternity wards (currently set at 1) and how many people may attend funerals (not more than 20). All regional units can report their findings on such issues to a national ethical support unit, which then announces national rules.

Gregoire Moutel, professor of medicine at Caen and Rouen University Hospital, who leads the Normandy ethical support unit, says, "One of our roles is to provide clarity and stop debate over why there is one rule in one part of the country and a different rule somewhere else." Some of the unit's decisions are given verbally — when they are urgent—and some others, such as the decisions on rules for maternity wards and funerals, are recorded in writing.

"We are here to help medical staff respond to the demands of the public and provide a space for public debate on these issues," Moutel told The BMJ. "This will help when it comes to managing the aftermath of this crisis."

Competing interests: I have read and understood BMJ policy on declaration of interests and have no relevant interests to declare.

Provenance and peer review: Commissioned; not externally peer reviewed.

1 National Advisory Committee on Ethics. Covid-19-Contribution du Comité Consultatif National D'éthique: Enjeux éthiques face à une pandémie [Contribution of the National Consultative Ethics Committee: Ethical issues facing a pandemic]. 13 Mar 2020. https:// www.ccne-ethique.fr/sites/default/files/reponse_ccne_-_covid-19_def.pdf. (In French.)

2 Andone D. New York will allow two patients to share a single ventilator. CNN $2020 \mathrm{Mar}$ 26. https://edition.cnn.com/2020/03/26/health/splitting-ventilators-coronavirus/index.html. Published by the BMJ Publishing Group Limited. For permission to use (where not already granted under a licence) please go to http://group.bmj.com/group/rights-licensing/ permissions 